\title{
Rainfall and run-off in the Derwent Valley to Yorkshire Bridge, Derbyshire
}

by

\author{
R. W. S. Thompson, B.Sc., M.I.C.E. \\ and \\ K. J. H. Saxton, M.A., A.M.I.C.E.
}

Mr R. W. Herschy (Hydrologist, Lothians River Purification Board) wrote that the Authors had made a valuable contribution to hydrology in this country from records of rainfall and run-off over a period of 56 years.

41. The light which the rainfall figures shed on over-exposure before 1934 was most interesting and losses were extremely high. It was noted that the turf wall did not cure that but only mitigated.

42. The Authors suggested in $\S 33$ that 16 gauges, including five daily, were sufficient for an initial period of ten years in such an area ( 49 sq. miles). The comparable figure from "The determination of general rainfall over an area' 5 was 25 , six of which should be read daily. The Authors followed that up by suggesting that after this initial period, four gauges should suffice. It was doubtful whether the Authors had proved that point in the Paper. Mr Herschy recognized that there was a school of thought among engineers who believed that, once sufficient run-off data was obtained, rainfall figures would become redundant. He hoped the Authors agreed with him that to fully understand the water resources of the country, all aspects of the hydrological cycle must be studied and that, in this connexion, the existing rainfall coverage should be increased.

43. Plotting the run-off against rainfall from Table 5, the line of best fit had a tangent of 1 and an equation of $A=R-17$, where $A$ was the run-off and $R$ the rainfall, (see Fig. 7).

44. It was interesting to compare that equation with that of Dr R. M. Gorrie's equation of $A=\frac{7}{8} R-8$ for Scottish rivers ${ }^{6}$ and E. C. Bilham's equation of $A=0.57 R-6.05$ for the Thames Basin. These lines were reproduced approximately in Fig. 7. It was obvious that these equations could only be near approximations, but they helped to illustrate the characteristics of the catchments.

45. The Authors stated in $\S 24$ that the records of run-off until the early 1920s were 'at least as accurate as the best river measurements by means of current meter and stage discharge curves'. Mr Herschy, however, thought it true to suggest that many hydrologists, particularly in America and in Europe, believed that a stable river section with sound control, natural or artificial, gave the most accurate discharge records. With the weir (or flume) there would always remain some measure of doubt about the formula even if the formula had been derived from a model test, and there would appear to be a growing feeling that such measuring structures should be re-calibrated by current meter in the field.

46. Captain W. N. McClean stated in the discussion to Mr Edward Sandeman's paper ${ }^{1}$-it was interesting to note that Clemens Herschel and Robert E. Horton also

* Proc. Instn civ. Engrs, vol. 25, June 1963, pp. 147-164. 
attended-that no mathematical formula could suffice without actual measurement of velocity and P. A. Morley Parker ${ }^{7}$ confirmed this feeling when he stated that no weir capable of practical construction discharged water according to the law $H^{3 / 2}$.

47. The formula for the Yorkshire Bridge weir was

$$
Q=\frac{2}{3} M L H \sqrt{ }(2 g H) .
$$

The velocity of approach was neglected up to $H=1.00 \mathrm{ft}$, and $M$ varied between 0.66 at $H=0.10 \mathrm{ft}$ and 0.614 at $H \geqslant 1.00 \mathrm{ft}$. For heads above $1.00 \mathrm{ft}$ the formula used was

$$
\frac{2}{3} M L H \sqrt{ }(2 g) \sqrt{ }\left(H+0.035 V^{2}\right)
$$

to include for velocity of approach. The percentage error in neglecting velocity of approach was larger for low heads than for high heads, but in this case provided the pool behind the $30-\mathrm{ft}$ weir was kept at $4.5 \mathrm{ft}$ deep below sill level, the velocity of approach error would be less than $1 \%$ for heads up to $1.00 \mathrm{ft}$. Deposits of gravel etc., however, could have the effect of raising this error towards $5 \%$ and at the same time, altering coefficient $M$. These errors might or might not have had opposite signs.

48. Mr Herschy felt sure that the discharge coefficients obtained for the modified weir would be of interest to hydrologists and asked if either of these two weirs were at any time checked by current meter; if so, did the results agree with the formulae? It would also be interesting to learn the condition of the weir crest during the period

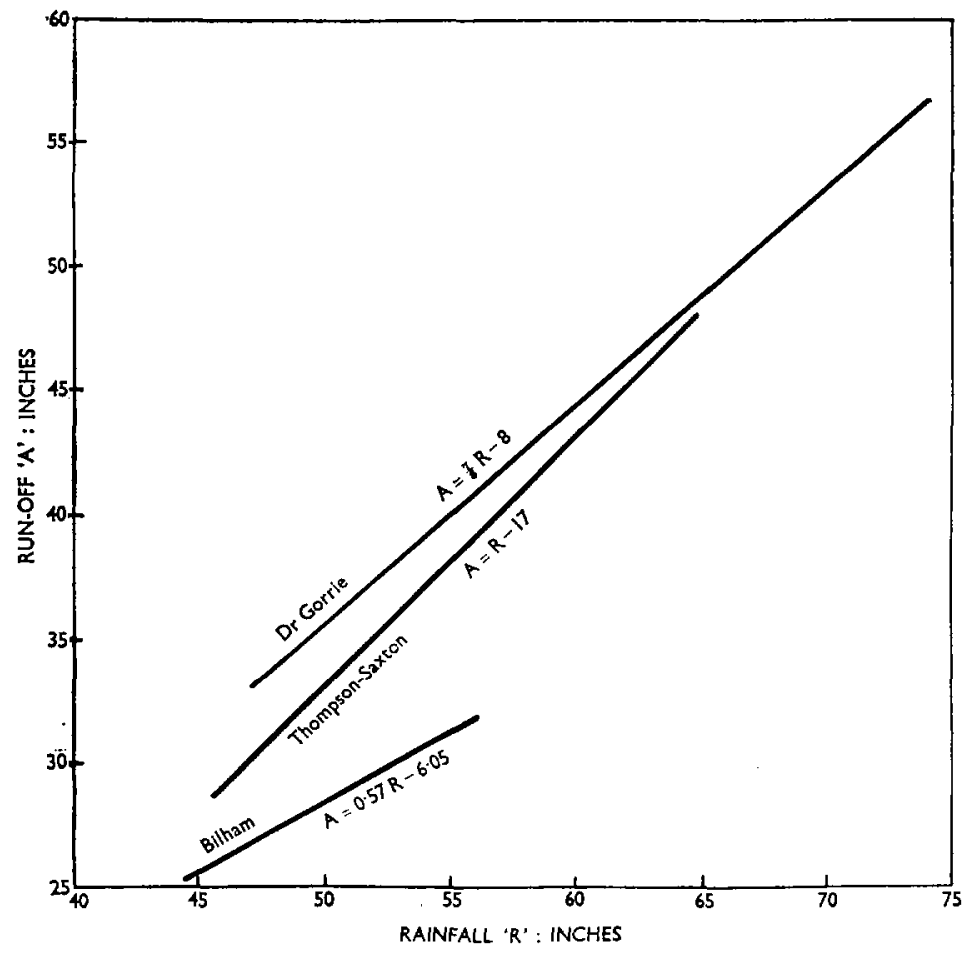

Fig. 7: RAINFALL-RUN-OfF EQUations 
1905-1936 and whether the crest required to be renewed. It was noted that Fig. 2 of Mr Sandeman's paper showed the direction of flow towards the weir at about $12^{\circ}$ oblique to the normal. Could this have had some effect in causing the difference in levels which the Authors mentioned in $\$ 22$ ?

49. Mr Herschy had reproduced in Fig. 8 a typical calibration curve for a broadcrested weir where $Q$ and $H$ were plotted logarithmically, values of $Q$ being obtained by current meter. The weir equation $Q=C L H^{2}$ plots as a straight line in the form

$$
\log Q=x \log H+\log K,
$$

where $K=C L$, the length of weir in this case being $24 \mathrm{ft}$. This equation could be solved either by substitution or directly from the curve since $x=\tan \theta$ and $K=Q$

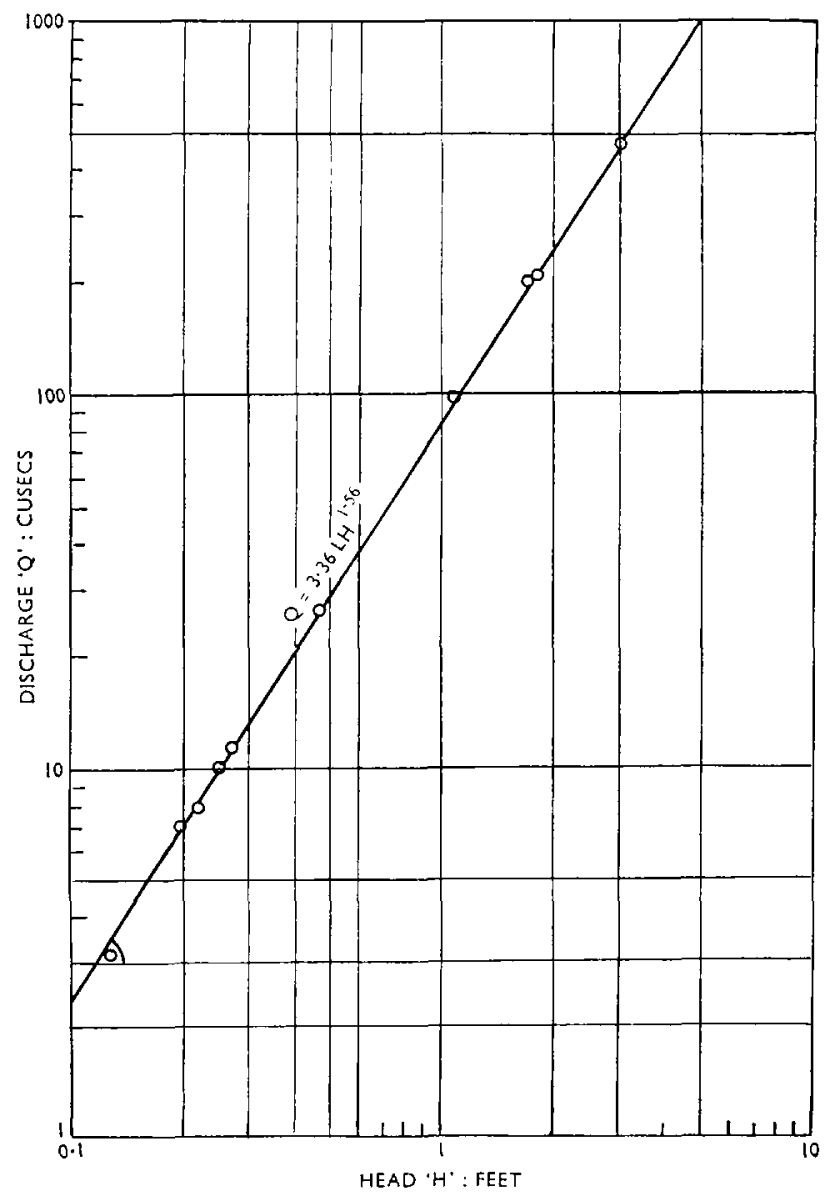

Fig. 8: WeIR CALIBRATION CURVE 
when $H=1.00 \mathrm{ft}$. In the case illustrated, $\tan \theta=1.56$ and $K=80.64$. Therefore $C=3.36$. The equation for the weir then became $Q=3 \cdot 36 L^{1 \cdot 56}$. At least one point on the curve should be checked annually. The rating table could be prepared either from the curve or from the formula.

50. Logarithmic plotting of weir discharge against head was probably first carried out by J. B. Francis in 1852 in model experiments to deduce the formula for the Merrimac River Dam. ${ }^{8}$

51. The main advantages in this method were that by altering the exponent of $H$, the weir coefficient became a constant, the velocity of approach was included in the coefficient, and the formula could be checked as necessary.

Mr Frank Law (Engineer, Fylde Water Board) wrote that the Authors deserved congratulations for stating so clearly the faults in the records over the past 60 years; particularly in the run-off from 1923 to 1931.

53. They rightly suggested that standing wave flume gauges were better than sharpedged weirs, but it was possible that their opinion would not have been quite so favourable to flumes if the Ladybower Dam had not been constructed just upstream of their flume in the 1930s.

54. This reservoir must have caught most of the debris which otherwise would have formed a high bank just upstream of the flume, thus interfering with true level recording.

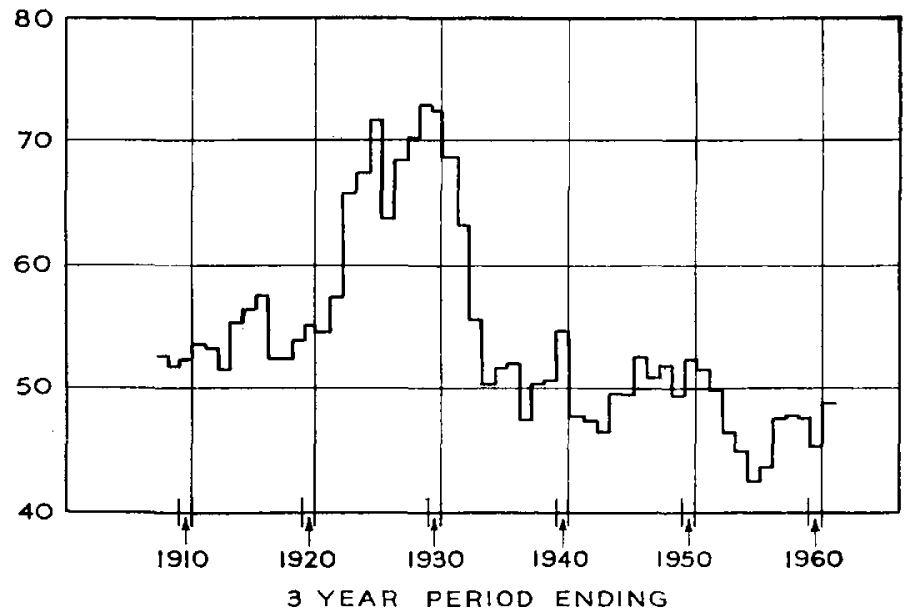

Fig. 9: APPARENT LOSSES OVER 3-YEAR PERIODS

55. In $\S 37$ the Authors stated that in times of high flood, fine silt and peaty matter could cause trouble by blocking float-wells. The blockage trouble was caused mainly by silt being deposited in the pipe joining the float-well to the channel and occurred far more often than was realized because the blockage cleared when the river level dropped. If these troubles had occurred despite the presence of Ladybower Dam, they would have been far more acute in a stream without a reservoir.

56. There was a great need for a means of recording levels accurately without a large float-well - possible by using a 4-in.-dia. float in a 6-in.-dia. float tube with electrical servo-mechanism to operate a punched-tape recorder.

57. The Authors had suggested in $\$ 29$ that the 'apparent errors' were 'very erratic and prior to 1923 much too low'. The latter comment did not seem to be 
true. The mean for 1906-1921 was 17.91 in. as compared with 16.36 in. for the period 1934-61, which the Authors appeared to consider reliable.

58. The variation in 'apparent loss' was clearly seen if plotted as 3-year running totals as in Fig. 9. It would almost seem that the losses had tended to decrease as the latter period progressed, and the Authors' comments upon this would be appreciated, particularly if they had any estimates of annual evaporation calculated by Penman's formula over the same period.

Mr C. F. Lapworth (Partner, Herbert Lapworth Partners) wrote that it was frequently assumed that in areas of high rainfall, such as the Derwent Valley, the losses from a catchment were approximately the same as the 'potential evaporation' from the area. 'Potential evaporation' meant the evaporation which would take place from a surface of short grass which was never short of water.

60. Fig. 10 showed a comparison month-by-month between

(a) the average loss-rainfall minus run-off-from the Derwent drainage area for the 28 years, 1934-61, a period when rainfall and run-off figures were considered to be accurate, and

(b) the average potential evaporation calculated by Penman's method ${ }^{9}$ from weather data at Buxton, as published in the Manual of British Water Engineering Practice. ${ }^{10}$ Buxton is about 15 miles to the south-west and at an elevation similar to the average of the Derwent catchment.

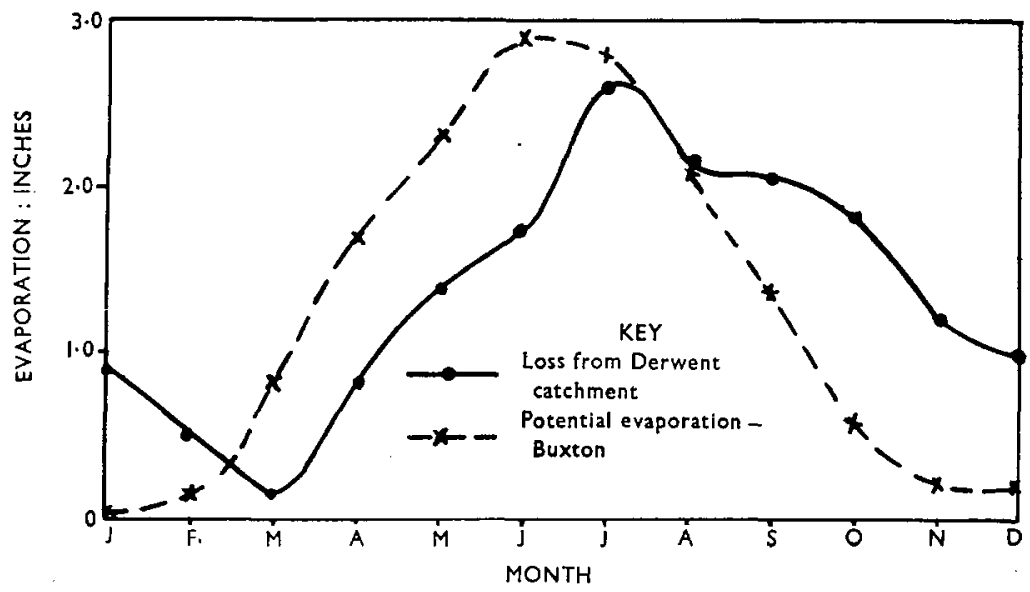

Fig. 10

61. There was only about 1 in. difference between the totals for the year, but the diagram showed that the monthly figures bore little relation to one another.

62. Snow lying on the catchment would result in delayed run-off but the differences could not be accounted for in this way.

63. Only in the months April to August did the average potential evaporation (which does not vary greatly from year to year) exceed the rainfall in the month. The average soil moisture deficit for these months was $0 \cdot 1,0 \cdot 2,0 \cdot 4,0 \cdot 1$, and $0 \cdot 2$, total 1.0 in. It was clear that the soil was at or near field capacity even in the summer months. It would appear that the difference shown in Fig. 10 could not be due to variations in soil moisture. 
Mr R. L. Harrison (Engineer and Manager, Manchester Corporation Waterworks) wrote that the particular catchment area which was dealt with in the Paper, and also the adjoining Longdendale Catchment of the Manchester Corporation Waterworks, had both been useful sources of information as to rainfall and run-off on this part of the Pennines for very many years. The Authors were to be congratulated on recording the information gathered over the past 60 years, indicating also the apparent annual losses noted.

65. It was of historical interest to note that Mr J. F. Bateman, who was responsible for the installation of the first gauge at Woodhead in 1847, and referred to in the Paper, had earlier, during 1840 and 1841, taken rainfall observations at four stations in connexion with the Glossop Reservoirs, which were given in a paper contributed to the Literary and Philosophical Society of Manchester in $1844 .^{3}$ One of the stations, in the valley of the River Derwent, at Bamford-cum-Hathersage, about $300 \mathrm{ft}$ above the sea, described in Bateman's paper as 'easterly foot of hills in the valley of the Derwent, mean of 1840 and 1841 ' recorded the mean annual result of $40 \cdot 85$ in. Details of the gauges used were given by J. F. Bateman. ${ }^{4}$

66. Incidentally, it was interesting to find in this same reference that before this date, Mr Bateman proved, to his own satisfaction, that previous records of rainfall in the Manchester and south-east Lancashire area, published by Dr Dalton, were inaccurate, mainly because of the unsuitable siting of the rain gauges upon which the records were based. In many instances these gauges were found to be situated in such elevated positions as on the ridges of houses. Mr Bateman, at his own expense, maintained a system of check gauges, fixed at ground level, which showed that approximately $50 \%$ more rain was collected in the latter gauges than in those in the exposed elevations.

67. Obviously the location of gauges had an enormous effect on their recordings, and the fewer the gauges employed, the more marked would be the effect of any change of location. This led Mr Harrison to enter a word of caution concerning $\$ 34$ of the Authors' conclusions, where in the light of recent experience, the assertion that a few daily gauges could be used to give a good representation of the mean catchment rainfall was not entirely borne out on the Longdendale Catchment. Here, the catchment of 19300 acres had 20 rain gauges of which four were read daily--two of which having check recording gauges.

68. It had been found that the annual mean of the four daily gauges averaged $82.4 \%$ of the mean of the whole catchment during the years 1935 to 1959 , and that a single gauge (that at Woodhead) was $88.3 \%$ of the catchment rainfall. Up to 1959 , it had been accepted that these ratios would give reasonable results.

69. In November 1959 at the suggestion of the Meteorological Office, the Woodhead gauge was moved some $20 \mathrm{yd}$ distance only to a new site, in a slightly less exposed position. During each of the three years 1960 to 1962 , there had been a distinct change in these relationships, in that the mean of the four gauges during each of those years was $87.5 \%$ and that at Woodhead was $100.7 \%$ of the catchment mean.

70. Apart from the relatively small change in location already referred to, there was nothing to account for the change in the formerly accepted relationships, except possibly a change in the weather pattern.

71. After studying closely many such Pennine catchment areas, Mr Harrison was convinced that actual measurement of run-off was the only reliable means of assessing the catchment, the run-off to be correlated to rainfall figures on permanently established stations.

The Authors wrote in reply that, as a general proposition, they agreed with $\mathrm{Mr}$ Herschy that the existing rainfall coverage of the country should be increased, but the real need was surely in regions where there were no gauges, or where existing gauges were 5 miles or more apart. It was these regions which eventually might have to 
provide the additional water resources of the country. The need for more river gauges was even greater.

73. Concerning the number of gauges on a catchment similar in character to that to Yorkshire Bridge, the Authors stated in $\S 33$ that gauges were also required outside the catchment. If these were taken into account, the number suggested did not disagree greatly with the recommendations in the Report ${ }^{5}$ referred to by $\mathrm{Mr}$ Herschy.

74. In $\S 24$ the Authors were referring to the Derwent catchment in particular, and it would be extremely difficult to find a site north of Yorkshire Bridge where there was 'a stable river section with sound control'. It would also be impossible to measure by current meter flows exceeding the order of 1000 cusecs, because they' occurred at unpredictable intervals and the velocities were very high. Experience had shown that such flows were not steady for more than 10 min even at the peak of a flood.

75. A search for the discharge coefficients for the modified 30 -ft and 90 -ft weirs, demolished in 1936, had proved unsuccessful, but it was known that the weirs were not checked by current meter, but were calibrated by means of a large-scale model. The obliquity was probably a factor in causing unequal water levels over the two weirs, but under the circumstances of Figs 2 and 3 , the primary reason was the high level of the river bed upstream of the weirs.

76. Mr Herschy would be interested to know that the original plot of the calibration curve for the Yorkshire Bridge flume was on a logarithmic basis.

77. In reply to $\mathrm{Mr}$ Law, the Authors agreed that the Yorkshire Bridge flume gauge was favourably situated in being close to the outlet of a large reservoir. But this did not apply between the time of the construction of the gauge in 1935 and the commencement of impounding in 1943. During that period the normal 'run-of-theriver' passed through it, and following the demolition of the original Yorkshire Bridge weir, a considerable accumulation of stones and gravel was scoured away from the river bed and gradually reached the approach channel. To deal with that abnormal situation, a drag-line excavator was used in addition to the normal method of scouring through the by-pass culvert that was provided for the purpose. Where, as in this case, there was a small 'bottom contraction', or 'hump', in the floor of the flume, and even where it was level, some part of the bed load might be deposited in the upstream channel during the recession of a flood. A by-pass culvert of useful size, if practicable, was therefore recommended.

78. Stoppage of the pipe between the upstream channel and the float-well by peat in suspension had only occurred once, that occasion being in October 1959, when the reservoir was very depleted and was beginning to fill. The Authors would nevertheless agree with $\mathrm{Mr}$ Law that there was a need for a means of recording water levels without the use of a large float-well. Perhaps in difficult cases (but where a reliable supply of electricity was available), both float-well and pipe could be dispensed with by following a method that was believed to be used in the measurement of the flow of sewage. This consisted of blowing a steady stream of air through a small hole in the channel wall just below zero level, and recording the air pressure just inside the orifice.

79. With reference to Mr Law's suggestion that it was, not true that the apparent losses prior to 1923 were much too low, the mean of these annual losses for the period 1906-1921 was 11.36 in.; this figure being obtained by deduction of the figures in Table 4 from those in italics in Table 1 . The mean of 17.91 in. stated by Mr Law was obtained by using the Authors' estimated figures of rainfall and not the measured rainfall. The Authors considered the reasonable agreement between 17.91 in. and 16.36 in. for the period 1934-1961 supported their estimation of the rainfall for the earlier period.

80. It had not been possible to calculate the annual evaporation by Penman's formula since records of sunshine and wind over the catchment were not available. 
81. Concerning the suggestion that the losses seemed to have decreased as the period 1934-1961 progressed, the Authors had calculated by the method of 'least squares' the trend for the period. This showed an annual decrease of less than 0.06 in. which the Authors considered insignificant.

82. Since the Paper was written, a better estimate of the losses, and hence the run-off, for the period 1922-31 had been attempted. During that period errors in the measurement of the flow at Yorkshire Bridge were known to have occurred, as had been stated in $\S 23$ of the Paper. Corrections for individual months appeared to be of dubious value, but the correlation coefficient between annual totals of rainfall (as now estimated in the case of the years 1906-1921) and losses was found to be significant at the $10 \%$ level. The new estimates of annual run-off and loss were as follows:

\begin{tabular}{|c|c|c|c|}
\hline \multicolumn{2}{|l|}{ Year } & $\begin{array}{c}\text { Estimated } \\
\text { run-off } \\
\text { in. }\end{array}$ & $\begin{array}{c}\text { Estimated } \\
\text { apparent } \\
\text { loss, in. }\end{array}$ \\
\hline 1922 & . & $40 \cdot 6$ & $17 \cdot 1$ \\
\hline 1923 & . & $49 \cdot 4$ & $17 \cdot 8$ \\
\hline 1924 & . & $34 \cdot 7$ & $16 \cdot 7$ \\
\hline 1925 & . & $37 \cdot 5$ & 16.9 \\
\hline 1926 & . & $35 \cdot 3$ & 16.7 \\
\hline 1927 & . & $43 \cdot 5$ & $17 \cdot 3$ \\
\hline 1928 & . & $44 \cdot 3$ & $17 \cdot 4$ \\
\hline 1929 & . & $35 \cdot 9$ & $16 \cdot 8$ \\
\hline 1930 & . & $48 \cdot 1$ & $17 \cdot 7$ \\
\hline 1931 & . & $48 \cdot 9$ & $17 \cdot 8$ \\
\hline
\end{tabular}

83. Using the above figures in place of those shown for those years in Table 5 of the Paper, the following averages for 56 years were obtained:

$\begin{array}{ll}\text { Average annual rainfall } & 54.91 \mathrm{in} . \\ \text { Average annual run-off } & 37.98 \mathrm{in} . \\ \text { Average annual loss } & \mathbf{1 6 . 9 3} \mathrm{in} .\end{array}$

84. The Authors were interested to know that rainfall in the Derwent Valley was measured as long ago as 1840 . The figure of 40.85 in. for Bamford, quoted by $\mathrm{Mr}$ Harrison, was similar to the 1916-1950 average of 39.8 in. at the Engineer's Office gauge in Bamford and the 1934-1961 average of 40.28 in.

85. It was a fact that readings of rain gauges were liable to be affected by differences of siting which could appear to be insignificant, but a gauge which was tolerably well sited could be expected to give consistent readings whether or not they indicated the true rainfall on the surrounding area.

86. The Authors had used the readings of the Woodhead gauge since analysis showed they had a close relationship with the general rainfall on the northern part of the catchment to Yorkshire Bridge. They thought it regrettable that the Woodhead gauge, which had records extending for more than 100 years, should have recently been moved. Could not an additional gauge be maintained in the original position?

87. According to the Manual, ${ }^{10}$ the Buxton figures used by Mr Lapworth were subject to some doubt, but his comparison was interesting since it showed a phaseshift of some 6-8 weeks throughout most of the year. The Authors agreed this might be due partly to delayed run-off in the winter months, but they considered it also indicated that, in the catchment to Yorkshire Bridge, there was a substantial amount of ground storage.

88. Estimation of the yield of a catchment from run-off data made allowance for ground storage, and this exemplified the paramount importance of run-off records. 


\section{REFERENCES}

3. J. F. Bateman. Observations on the relation which the fall of rain bears to the water flowing from the ground. Mem. Manchr lit. phil. Soc., vol. 7, 1846, pp. 157-190.

4. J. F. Bateman. 'The history and description of Manchester waterworks.' J. T. Day, Manchester and E. \& F. N. Spon, London, 1884.

5. Report of the Joint Committee to consider methods of determining rainfall over any area. Trans. Instn wat. Engrs, vol. 42, 1937, pp. 231-259. Discussion: pp. $260-276$.

6. R. M. GorrIE. The need for river-flow studies. Nature, vol. 182, 1 November, 1958, pp. 1193-5.

7. P. A. Morley PARKer. 'The control of water.' Routledge \& Kegan Paul, London, 1949.

8. R. E. Horton. Weir experiments, coefficients and formulas. Wat.-Supp. (Irrig.) Pap., Wash., no. 200, 1907.

9. H. L. Penman. Evaporation over the British Isles. Quart. J. roy. met. Soc., vol. 76, October 1950, pp. 372-387.

10. W. O. SKEAT (ed.). 'Manual of British water engineering practice.' W. Heffer, Cambridge, 1961, Chapter 3, Section III. 